\title{
Novel inorganic composite materials for lithium-ion batteries
}

\author{
Xinhua Liu ${ }^{1}$, Chandramohan George ${ }^{1}$, Huizhi Wang ${ }^{2}$, Billy Wu ${ }^{1}$ \\ ${ }^{1}$ Dyson School of Design Engineering, Imperial College London. UK \\ ${ }^{2}$ Department of Mechanical Engineering, Imperial College London. UK
}

\section{Introduction}

Lithium-ion batteries (LIBs) have revolutionised the way we interact with the world around us. This is in part due to their unrivalled energy density and stability relative to other energy storage chemistries such as lead-acid, nickel-metal hydride and nickel cadmium batteries. Given the drive to reduce greenhouse gas emissions from road transport, LIBs have now transitioned from application in consumer electronics to become the most critical component for electric vehicles $(\mathrm{EV})$ however improvements in energy and power density, cost reduction and lifetime are still required. The key aspects of a LIB which define its performance are mainly the anode, cathode and electrolyte though development of the separator and current collectors are also key considerations. In the vast majority of commercially available LIBs the anode consists mostly of graphite and the cathodes mostly of layered transition metal oxides with an organic electrolyte facilitating the lithium-ion transport between the two electrodes. This chapter provides an overview of the state-of-the-art in developing inorganic composite materials for LIBs and concludes by highlighting the current challenges as well as the potential opportunities in the field.

\section{Advances in Layered Cathode Materials}

Early generations of LIBs predominantly used lithium cobalt oxide (LCO) as the cathode material of choice due to its favourable theoretical capacity $(274 \mathrm{mAh} / \mathrm{g})$ [1] which much of the work being pioneered by Professor John Goodenough. However, $\mathrm{Li}_{1-x} \mathrm{CoO}_{2}$ as lithium is removed from LCO chemical stability issues arise when $x>0.5$ resulting in limited practical capacities [2] which when compounded with concerns over cobalt availability means their application in automotive applications is progressively limited. To overcome the issues with the high cost of cobalt, manganese was then explored as an alternative low cost cathode material with the lithium manganese oxide $\left(\mathrm{LiMn}_{2} \mathrm{O}_{4}\right)(\mathrm{LMO})$ chemistry being used in the Nissan Leaf. However, $\mathrm{LiMn}_{2} \mathrm{O}_{4}$ only has a theoretical capacity of $154 \mathrm{mAh} / \mathrm{g}$ with a reversible capacity limited to $\sim 120 \mathrm{mAh} / \mathrm{g}$ due to material degradation issues relating to $\mathrm{Mn}^{3+}$ dissolution with deep discharges [3].

Lithium iron phosphate $\left(\mathrm{LiFePO}_{4}\right)(\mathrm{LFP})$ is another commonly used cathode material that is attractive due to its high stability during intercalation/deintercalation as well as its costeffectiveness. The material has a 1D olivine structure and a theoretical maximum capacity of $169 \mathrm{mAh} / \mathrm{g}$. Differences between theoretical and experimental results stem from the poor lithium diffusivity through the $\mathrm{LiFePO} / 4 / \mathrm{FePO}_{4}$ interface as well as the fact that $\mathrm{LiFePO}_{4}$ is an electronically insulating phase [4]. In more recent years, many of these hurdles around the use of LFP have been overcome through the development of nano-LFP with carbon coatings [5] which increase the electronic conductivity as well as minimise lithium diffusion pathways across electrodes.

Given the limited capacity that was possible from LCO, LMO and LFP cathodes, there has been significant interest in developing higher energy density materials for LIBs. Subsequent efforts focused on layered oxide materials with structures similar to LCO but with the substitution of the expensive cobalt with nickel or manganese. Approaches have included mixing $\mathrm{LiNiO}_{2}$ and $\mathrm{LiMnO}_{2}$ in a 1:1 ratio to form layered $\mathrm{LiNi}_{0.5} \mathrm{Mn}_{0.5} \mathrm{O}_{2}$. Various studies have 
shown that this material system differs from the pure layered oxide materials which have a pure lithium layer and a pure transition metal oxide layer. However, synthesis of phase pure materials is a challenge with approximately $8-10 \%$ of the nickel ions in $\mathrm{LiNi}_{0.5} \mathrm{Mn}_{0.5} \mathrm{O}_{2}$ being found in the lithium layers. This transition metal migration from the metal oxide layer to the lithium layers then leads to blockages of the lithium diffusion pathways resulting in diffusion coefficients nearly 1 order of magnitude lower than that reported in LCO cathodes [6]. Subsequent works on stabilisation of the crystalline structure of the battery materials then led to the now commercialised use of combinations of nickel, cobalt, manganese and aluminium in modern day LIBs. Of these, Lithium Nickle-Manganese-Cobalt Oxides $\left(\mathrm{LiCo}_{0.33} \mathrm{Ni}_{0.33} \mathrm{Mn}_{0.33} \mathrm{O}_{2}\right)$ (NMC) and the lithium Nickel-Cobalt-Aluminum Oxide (NCA) are the most commonly use in automotive applications. However, despite the favourable performance of NMC and NCA materials which has lead them to widespread usage in EV applications there is still a need to develop better battery materials with high storage capacity and chemical stability. Table 1 lists these materials and their key performance values for comparison.

Table 1: Properties of different commercialised lithium-ion cathode materials adapted from Nitta et al. [1]

\begin{tabular}{|l|l|l|l|l|}
\hline Structure & Formula & $\begin{array}{l}\text { Specific capacity } \\
/ \mathrm{mAh} / \mathrm{g}^{*}\end{array}$ & $\begin{array}{l}\text { Volumetric capacity / } \\
\mathrm{mAh} / \mathrm{cm}^{3 *}\end{array}$ & $\begin{array}{l}\text { Nominal } \\
\text { voltage / V }\end{array}$ \\
\hline Layered & $\mathrm{LiCoO}_{2}$ & $274 / 148$ & $1,363 / 550$ & 3.8 \\
\hline Layered & $\mathrm{LiCo}_{0.33} \mathrm{Ni}_{0.33} \mathrm{Mnn}_{0.33} \mathrm{O}_{2}$ & $280 / 160$ & $1,333 / 600$ & 3.7 \\
\hline Layered & $\mathrm{LiNi}_{0.8} \mathrm{CO}_{0.15} \mathrm{Al}_{0.05} \mathrm{O}_{2}$ & $279 / 199$ & $1,284 / 700$ & 3.7 \\
\hline Olivine & $\mathrm{LiFePO}_{4}$ & $170 / 65$ & 589 & 3.4 \\
\hline Spinel & $\mathrm{LiMn}_{2} \mathrm{O}_{4}$ & $148 / 120$ & 596 & 4.1 \\
\hline
\end{tabular}

${ }^{*}$ Theoretical/typical in commercial cells

\section{a. Nickel-rich layered oxides}

The conventional NMC chemistry uses a stoichiometric ratio of 111 with regards to nickel, manganese and cobalt, however research efforts are continuing to investigate means of increasing the energy density further. One heavily researched area is to increase the nickel content in order to increase the capacity and operating voltage with commercial traction in the 622 chemistry and 811 in coming years however there are still a number of technical challenges to overcome. Nickel-rich layered oxides (NLO) generally exhibit discharge capacities in the region of 200-250 mAh. ${ }^{-1}$ and a high operating voltage $\sim 3.8 \mathrm{~V} \mathrm{vs} \mathrm{Li}^{\prime} \mathrm{Li}^{+}[3]$ however, the main obstacle to practical implementation is their stability. Various research efforts have investigated cation substitution of other transition metal ions such as Co, Fe, Mn, $\mathrm{Ti}, \mathrm{Mg}$ and $\mathrm{Al}$ for $\mathrm{Ni}$ in the form $\mathrm{LiNi}_{1-\mathrm{x}} \mathrm{M}_{\mathrm{x}} \mathrm{O}_{2}$. These materials target increased chemical stability without oxygen loss by avoiding significant overlap of the $\mathrm{Ni}^{3+/ 4+}$ redox energy with the top of the $\mathrm{O}^{2-}: 2 \mathrm{p}$ band [3]. Since stoichiometric $\mathrm{LiCoO}_{2}$ and $\mathrm{LiNiO}_{2}$ are isostructural, with the ionic radii/electronegativity of $\mathrm{Ni}^{3+}$ and $\mathrm{Co}^{3+}$ being very similar $0.56 \AA / 1.91$ and $0.545 \AA / 1.88$, respectively, a solid solution of $\mathrm{LiNi}_{1-x} \mathrm{Co}_{x} \mathrm{O}_{2}$ can be readily formed over the entire compositional range [7-10]. Here it was found that Co substitution is beneficial for reducing the cation disorder relative to pure $\mathrm{LiNiO}_{2}$ and thus stabilising the material when (de)intercalated.

Mn substitution on the other hand was found to be less compatible compared to Co substitution, with solid solutions only forming at compositions of $\mathrm{LiNi}_{1-x} \mathrm{Mn}_{\mathrm{x}} \mathrm{O}_{2}$ when $\mathrm{x}<0.5$. However, interest in Mn based materials remains an interest due to the low cost of the material with works later leading to the development of the ternary $\mathrm{LiNi}_{1-x-y} \mathrm{Co}_{x} \mathrm{Mn}_{y} \mathrm{O}_{2}$ materials. In this system, the $\mathrm{Ni}^{2+} /{ }^{3+}$ and/or $\mathrm{Ni}^{3+} /{ }^{4+}$ redox couples provide most of the reversible capacity with the Co improving the structural stability of the material and improving rate capability/capacity 
through prevention of $\mathrm{Ni}$ migration into the Li layers and also the $\mathrm{Co}^{3+}{ }^{4+}$ redox couple. $\mathrm{Mn}$ on the other hand remains electrochemically inert but stabilises the structure, especially at high delithiation states [11]. Because of the adventurous properties of the $\mathrm{LiNi}_{1-x-y} \mathrm{Co}_{x} \mathrm{Mn}_{\mathrm{y}} \mathrm{O}_{2}$ system, various cation ratios have been explored which are broadly summarised in Figure 1, with annotations representing the relative capacity from the different compositions. In the vast majority of cases, these materials are made through a co-precipitation method in a continuously stirring tank reactor.
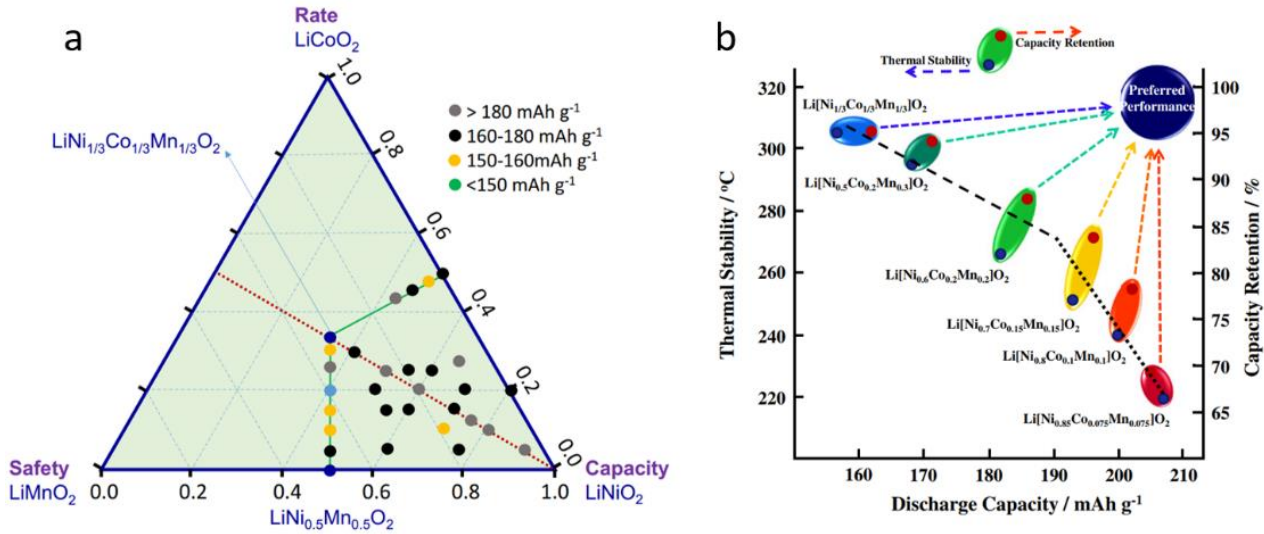

Figure 1: (a) Compositional phase diagram of $\mathrm{LiCoO}_{2}-\mathrm{LiNiO}_{2}-\mathrm{LiMnO}_{2}$ [12] and (b) relationship between capacity, thermal stability and capacity retention [13].
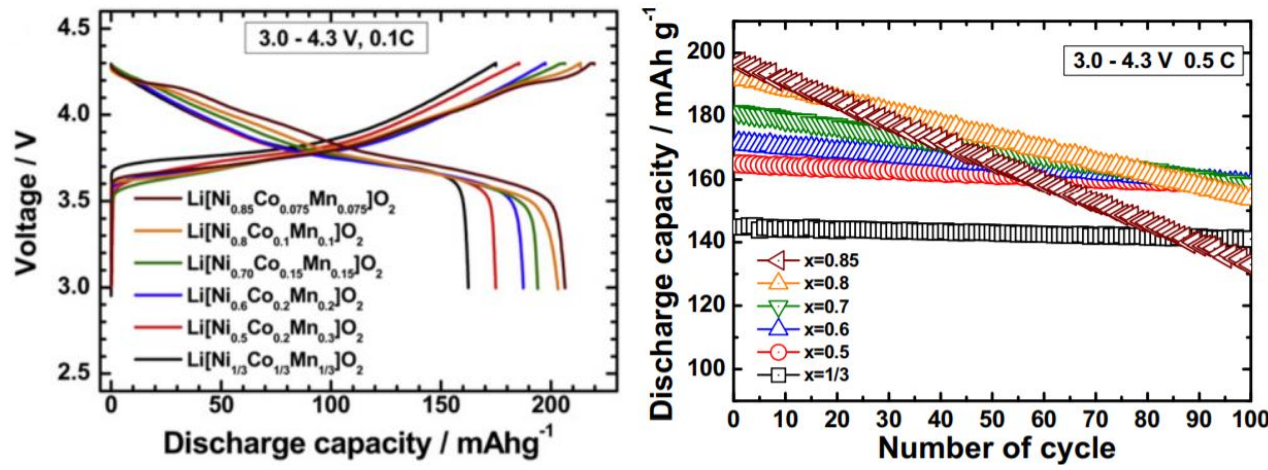

Figure 2: (a) Initial charge-discharge curves of a $\mathrm{Li} / \mathrm{Li}\left(\mathrm{Ni}_{x} \mathrm{Co}_{y} \mathrm{Mn}_{z}\right) \mathrm{O}_{2}$ cell $(\mathrm{x}=1 / 3,0.5,0.6,0.7$, $0.8,0.85)$ and (b) capacity retention of the various compositions at $25^{\circ} \mathrm{C}$ with a current density of $100 \mathrm{~mA} / \mathrm{g}$ [13]

More recent efforts have focused on functional grading of particles to get the advantageous aspects of each transition metal. For instance, Sun et al. [14] demonstrated the synthesis of a concentration-gradient NMC cathode where each particle has a central bulk which is Ni rich and a $\mathrm{Mn}$ rich shell with increasing $\mathrm{Mn}$ and $\mathrm{Co}$ as the surface is approached. In this configuration the Ni provides the capacity and the $\mathrm{Mn} / \mathrm{Co}$ provides thermal stability. Through this approach, an overall composition of $\mathrm{Li}\left(\mathrm{Ni}_{0.64} \mathrm{Co}_{0.18} \mathrm{Mn}_{0.18}\right) \mathrm{O}_{2}$ was synthesized which showed a reversible capacity of $209 \mathrm{mAh} / \mathrm{g}$ and an improved thermal stability compared to NMC811. However, due to differences in the volume changes with lithiation between the different compositions, it was found that this can exasperate the formation of micro cracks in the bulk of the material leading to challenges with long term capability. Research efforts have thus focused on means of mitigating this volume expansion mismatch through the development of core-shell gradient and full concentration gradient approaches. These 
approaches aim to minimise abrupt changes in composition and thus large volume changes, however add complexity in the manufacturing process.

Beyond doping with various combinations of $\mathrm{Ni}, \mathrm{Mn}$ and $\mathrm{Co}$, various other transition metals have been explored including $\mathrm{Ti}, \mathrm{Fe}, \mathrm{Mg}, \mathrm{Al}, \mathrm{Zn}, \mathrm{Ce}, \mathrm{Cr}, \mathrm{Cu}$ and $\mathrm{Mo}$ [3]. From a commercial perspective, $\mathrm{LiNi}_{0.8} \mathrm{Co}_{0.15} \mathrm{Al}_{0.05} \mathrm{O}_{2}$ (NCA) cathodes have received significant industrial attention and commercial success with Panasonic and Tesla. Here, Al doping was shown to be advantageous from a structural stability perspective due to the strong Al-O bonds which form and isostructural aspects of $\mathrm{LiAlO}_{2}$ relative to $\mathrm{LiNiO}_{2}$, whereby a complete solid solution can be formed with Al up to concentrations of 0.5 in a similar way to $\mathrm{LiCoO}_{2}$.

However, a major challenge with NLOs are generally at the electrode-electrolyte interfaces due to the higher operating potentials of these materials which can cause the decomposition of common organic electrolytes. However, studies have also found that bulk degradation of $\mathrm{Ni}$ rich materials can occur which are often related to the formation of cracks in the material, often at grain boundaries. This becomes increasingly problematic at high $\mathrm{Ni}$ contents when the volume changes are larger. This bulk fragmentation can then lead to isolation of regions of the active material and also exposure of more of the material to the electrolyte leading to more increase solid-electrolyte interphase (SEI) layer formation at the cathode.

The electrode-electrolyte interface is of particular importance in the long term lifetime performance of NLOs since the manufacturing process can cause the production of excess lithium oxides at the surface of the particles which can readily react with moisture and $\mathrm{CO}_{2}$ under ambient conditions producing $\mathrm{LiOH}$ and $\mathrm{Li}_{2} \mathrm{CO}_{3}$. In turn, when exposed to common organic electrolytes, this can lead to the formation of the cathode SEI which can hinder $\mathrm{Li}^{+}$ transport at the interface and also change the rheological properties of the active material slurry during the coating process. Moreover, the increased amount of $\mathrm{Ni}^{4+}$ ions at deeply delithiated states can further accelerate the electrolyte decomposition. To overcome these challenges various surface coating approaches have been considered which serves the purpose of preventing surface phase transitions and also to scavenge decomposition products such as hydrofluoric acid.

\section{b. Lithium-rich layered oxides}

Lithium-rich layered oxide (LRLO) materials are of interest due to their enhanced discharge (250-300 mAh.g $\left.{ }^{-1}\right)$ capacities over materials such as $\mathrm{LiCoO}_{2}\left(140 \mathrm{mAh} . \mathrm{g}^{-1}\right), \mathrm{LiNi}_{1 / 3} \mathrm{Co}_{1 / 3} \mathrm{Mn}_{1 / 3} \mathrm{O}_{2}$ $\left(160 \mathrm{mAh}^{-1} \mathrm{~g}^{-1}\right.$ and $\mathrm{LiMn}_{2} \mathrm{O}_{4}\left(120 \mathrm{mAh} \cdot \mathrm{g}^{-1}\right)$. However, challenges which include: oxygen loss from the lattice on the first charge, large first cycle irreversible loss, poor rate capability, side reactions and voltage decay still need to be overcome [15]. LRLOs often tends to behave either as a solid solution or nanocomposite of $\mathrm{Li}_{2} \mathrm{MnO}_{3}$ and $\mathrm{LiMO}_{2}$ where $\mathrm{M}$ is a collection of metals, often $\mathrm{Mn}, \mathrm{Ni}$ and $\mathrm{Co}$. Oxygen is lost and Li vacancies are created on the first charge through the migration of the transition metal oxides which leads to the gradual transition from the layered structure to a spinel-like phase. Surface coatings can help to stabilise the structure and protect the electrode from the electrolyte, however low rate capability and voltage decay is a key problem.

Hu et al. showed that [16] the average valence state of each type of transition metal cation in $\mathrm{Li}_{1.2} \mathrm{Ni}_{0.15} \mathrm{Co}_{0.1} \mathrm{Mn}_{0.55} \mathrm{O}_{2}$ is continuously reduced due to oxygen release. These reductions activate the lower voltage $\mathrm{Mn}^{3+} / \mathrm{Mn}^{4+}$ and $\mathrm{Co}^{2+} / \mathrm{Co}^{3+}$ redox couples in addition to the original $\mathrm{Ni}^{2+} / \mathrm{Ni}^{3+}, \mathrm{Ni}^{3+} / \mathrm{Ni}^{4+}$ and $\mathrm{O}^{2-} / \mathrm{O}^{-}$couples, thus leading to voltage fade. Through coating the material with $\mathrm{AlF}_{3}$, it was shown that oxygen release could be reduced, thus limiting the layered to spinel phase transition. During phase transitions from the layered to the spinel phase there is facile migration of $\mathrm{Mn}$ from the transition-metal plane to the Li plane [3]. Cation migration, 
especially to the lattice tetrahedral sites, was another proposed mechanism to explain the observed voltage fade[17]. Other works of note include Singer et al. [18] who used 3D Bragg coherent diffractive imaging to observe the nucleation of a mobile dislocation network in LRLO nanoparticles. It was shown that the dislocations form more readily in LRLO compared with traditional metal layered oxides, suggesting a link between defect density and the observed voltage fade effects. Singer et al. also showed that by annealing the cathode material the voltage recovers.

Other challenges with LRLO include oxygen release which can also have a detrimental impact on the microstructure of battery materials. Mu et al. [19] for instance showed that oxygen release and thus oxygen vacancies can lead to sporadic phase transformations from the layered structure to the spinel and/or rock salt structure to induce local stresses which can form inter- and intra-granular cracks. This is a particular issue at the surface of these LRLO particles which are in contact with the organic electrolyte.

\section{c. Mixed cation layered and doped cathodes}

Understanding the complex interaction of mixed cations $(\mathrm{Ni} / \mathrm{Mn})$ in layered cathodes is key to devise strategies against structural distortions causing voltage decay during battery cycling. In an early report, Grey and co-workers have reported metal clustering effects in mixed layered oxide $\left(\mathrm{LiNi}_{x} \mathrm{Mn}_{\times} \mathrm{Co}_{1-2 \times} \mathrm{O}_{2}\right)$, leading to an insulator-to-metal transition in the electrochemical profiles [20] of the material. Recently, Sun et al. proposed that based on a thermal annealing at $500{ }^{\circ} \mathrm{C}$ and testing of $\mathrm{LiNi}_{1 / 3} \mathrm{Co}_{1 / 3} \mathrm{Mn}_{1 / 3} \mathrm{O}_{2}$, there is an optimal degree of cation mixing ( $\left.\mathrm{Li} / \mathrm{Ni}\right)$ for improving the electrochemical performance of the layered material [21]. In the case of low $\mathrm{Li} / \mathrm{Ni}$ mixing, they noticed an increased tendency of layered to spinel phase transition, causing voltage decay. Alternatively, doping of alkaline metal or metal into mixed cations layered can be beneficial in terms of cycling stability. For example Aurbach and co-workers [22] reported that doping $\mathrm{Al}$ into the mixed cation layered phase can be carried out to yield $\mathrm{Li}_{1.2} \mathrm{Ni}_{0.16} \mathrm{Mn}_{0.51} \mathrm{Al}_{0.05} \mathrm{Co}_{0.08} \mathrm{O}_{2}$, which exhibited a more stable cycling performance compared to $\mathrm{Li}_{1.2} \mathrm{Ni}_{0.16} \mathrm{Mn}_{0.56} \mathrm{Co}_{0.08} \mathrm{O}_{2}$ (undoped), but this comes at the expense of decreased specific capacity. This was attributed to decreased unit cell parameters due to Al doping preventing the migration of transition metal ions that initiate phase transitions and this was further supported by Raman studies detecting the presence of spinel phase in the cycled undoped samples. Zhao et al. [23] reported that niobium doped layered oxides $\left(\mathrm{Li}_{1.2} \mathrm{Mn}_{0.54} \mathrm{Co}_{0.13} \mathrm{Ni}_{0.13} \mathrm{O}_{2}\right)$ not only exhibited comparable capacity but improved cycle performance and it was speculated that the relatively bigger $\mathrm{Nb}$ can enlarge the interlayer spacing leading to improved electron transport.

\section{Outlook}

Cathodes are the most crucial component in LIBs as they largely determine the battery energy and performance. From a cost and environmental standpoint, the aim is to replace Co with Mn but this is limited by issues such as Mn dissolution in the electrolyte during battery cycling. Interestingly, LFP offers exceptional stability and its inherent low conductivity can be circumvented by carbon coating. However, despite this advance, the energy density of LFP is still low, which triggered exploration of new cathode materials containing more than one cation. For example, layered oxides with $\mathrm{Ni}$ and $\mathrm{Mn}$, appear to be potential candidates but the presence of these cations in the same lattices often to leads to phase segregation and blocking of $\mathrm{Li}$ sites. Mixed cation ( $\mathrm{Ni}, \mathrm{Mn}$, Co) layered materials have gained more traction due to improved energy densities and are being widely deployed. However, voltage decay over battery cycling is a recurrent problem due to progressive cation migration and increased tendency of undergoing layered-to-spinel phase transformation. This is in part mitigated by ion doping, which tends to stabilise layered structures, but doping in large-scale could be 
problematic and compromises with the specific capacity. Ni rich layered compounds are appealing but they show increased tendency to react with electrolytes and the migration of $\mathrm{Ni}$ ions out of their sites blocks Li sites. Li rich layered oxides could be interesting but suffer from $\mathrm{O}_{2}$ release from the lattice during first charge and eventually phase transformation limits further application.

\section{Advances in Anode Materials}

Currently, graphite is the most frequently used anode material for commercial LIBs due to its many advantages such as: favourable layered structure, a flat and low voltage range, natural abundance and low cost. However, the graphite anode is limited by its theoretical capacity of $372 \mathrm{mAh} \mathrm{g}^{-1}$ and by its tendency to grow hazardous Li dendrites at low voltages causing battery short-circuit. This means the use of advanced anode materials is required to improve battery capacities as well as battery safety. 2D graphene-like nanostructures and several 2D inorganic materials have been extensively explored as battery anodes due to their high surface-to-mass ratio and unique physical and chemical properties, which can supply abundant Li-insertion sites/channels and shorten charge transport paths, enabling fast transport and storage of lithium ions. Such 2D anode materials mainly include transition metal oxides (TMOs), transition metal dichalcogenides (TMDs) and the transition metal carbides/nitrides (mainly MXenes).

\section{a. Transition Metal Oxides (TMOs).}

Transition metal oxide materials (TMOs), such as $\mathrm{Co}_{3} \mathrm{O}_{4}, \mathrm{NiO}, \mathrm{Fe}_{3} \mathrm{O}_{4}$, and $\mathrm{MnO}_{2}$, are widely investigated as lithium ion anodes because of their high theoretical capacities and relatively high power density. However, TMOs suffer from several problems: severe volume change, pulverization and agglomeration of primary particles, and their poor electronic conductivities that hinder the electrochemical reactions, leading to limited battery capacity. To address these challenges, metal oxides are then developed into nanostructures with different dimensions, such as the design of hollow and hierarchical structures, coating or through the combination of conductive buffer materials (e.g. carbon nanotubes and graphene nanosheets) with TMOs. Even so, TMOs do not seem to meet the high requirements for real-world application in LIBs. Alternatively, lithiated titanium oxides (LTO) become an important oxide based anode [24], exhibiting greater stability at extremely high rates (up to $\sim 100 \mathrm{C}$ ) but have higher operating voltages $\sim 1.4 \mathrm{~V}$, which decreases the full cell voltage, thus decreasing the energy density as well.

Recently, mixed transition metal oxide materials (MTMOs), referring to ternary metal oxides with two different metal cations, have attracted more attention as promising anode candidates owing to their mixed valence states and multi-redox reactions, higher electrical conductivities due to the relatively low activation energy for electron transfer between cations and alloying capabilities with lithium ions compared to physically mixed and single metal ion oxides. Because of the advantages of the 2D nanostructures as discussed previously, 2D holey MTMO nanosheets with tuneable porosity and inherent mechanical stability are considered to be promising anode candidates for many emerging applications in energy storage. Yu and coworkers recently reported important progress in the development of a series of porous 2D holey MTMO nanosheets with controllable pore sizes employing graphene oxides as sacrificial templates [25]. Figure 3 shows STEM images of $\mathrm{ZnMn}_{2} \mathrm{O}_{4}$ precursor/rGO and 2D holey $\mathrm{ZMO}$ nanosheets with interconnected $\mathrm{ZnMn}_{2} \mathrm{O}_{4}$ nanocrystals. This approach has been developed as a general and effective approach to synthesize a group of 2D holey TMO nanosheets, including simple TMOs, such as $\mathrm{Mn}_{2} \mathrm{O}_{3}, \mathrm{Co}_{3} \mathrm{O}_{4}$, and $\mathrm{Fe}_{2} \mathrm{O}_{3}$, and 2D holey MTMOs, such as $\mathrm{ZnMn}_{2} \mathrm{O}_{4}, \mathrm{ZnCo}_{2} \mathrm{O}_{4}, \mathrm{CoFe}_{2} \mathrm{O}_{4}$ and $\mathrm{NiCo}_{2} \mathrm{O}_{4}$. Benefiting from the 2D holey structures, these TMO nanosheets exhibit much improved rate capability and cyclic stability and coulombic 
efficiency as anodes in LIBs. For example, the as-prepared 2D holey $\mathrm{ZnMn}_{2} \mathrm{O}_{4}$ nanosheets showed rate capability of $770 \mathrm{mAh} \mathrm{g}^{-1}$ at $200 \mathrm{~mA} \mathrm{~g}^{-1}$ and a high capacity of $430 \mathrm{mAh} \mathrm{g}^{-1}(56 \%$ of capacity retention) at $1,200 \mathrm{~mA} \mathrm{~g}^{-1}$, while the control spinel $\mathrm{ZnMn}_{2} \mathrm{O}_{4}$ only maintains $32 \%$ and $6 \%$ capacity respectively.
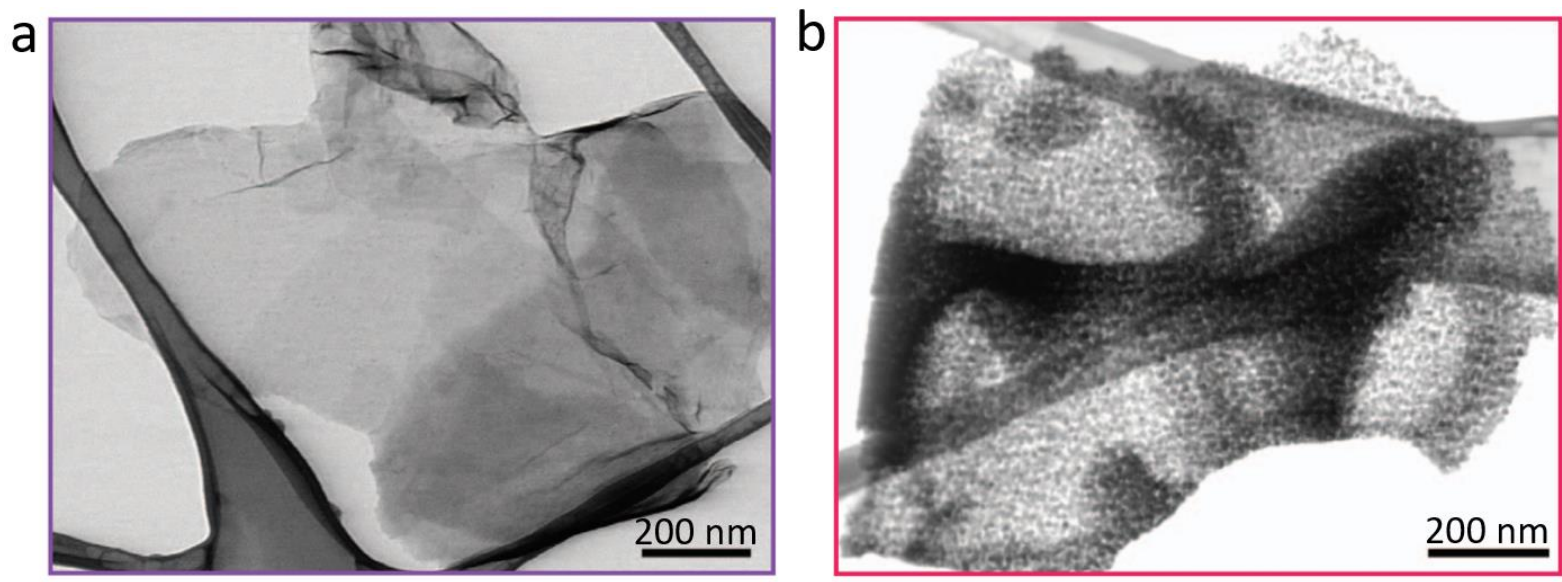

Figure 3. STEM image of ZMO precursor/rGO shows sheets-like morphology. (c) STEM image of $2 \mathrm{D}$ holey ZMO nanosheets shows holey nanosheets composed of interconnected ZMO nanocrystals [25].

The lithium-ion transport mechanism and associated phase transformation of 2D holey MTMO electrodes are further studied by using $2 \mathrm{D}$ holey $\mathrm{ZnFe}_{2} \mathrm{O}_{4}$ nanosheets and nanoparticles [26]. Additionally, in-situ TEM and XRD were combined with in-situ XAS measurement to investigate the enhanced ionic kinetics, mechanical properties, and morphology evolution of 2D holey MTMO nanosheets during the electrochemical cycling. The advantages can be summarized as: firstly, the holey 2D nanosheets with increased surface area, can accelerate the effective transportation of lithium ions because the continuous and interconnected holes within 2D nanosheets allow for liquid electrolyte diffusion into the bulk of the electrode materials, thus reducing solid-state lithium diffusion path length. Secondly, the wellinterconnected nanocrystals can also maintain continuous electron transport without the need of conductive agents (e.g. carbon) in the electrodes. The energy barriers for ion transport can be decreased and the kinetics of ion transport can be further improved due to the 2D porous nanosheets with an interlayer-expanded layer structure. Finally, these interconnected holes can effectively accommodate the volume changes during lithiation and delithiation processes, leading to enhanced cyclic stability and coulombic efficiency. Notably, this structure is particularly helpful for batteries experiencing high charge and discharge rates.

\section{b. Transition Metal Dichalcogenides (TMDs)}

Transition metal dichalcogenides (TMDs) are a large group of compounds which are mostly naturally layered and can be either exfoliated from the bulk TMDs or synthesized via bottomup approaches to obtain single or several layered thin 2D nanosheets (e.g., $\mathrm{MoS}_{2}, \mathrm{WS}_{2}$, $\mathrm{MoSe}_{2}$, and $\mathrm{WSe}$ ). Although their theoretical capacities are much higher than that of graphite, many TMDs (e.g., FeS, $\mathrm{FeS}_{2}$, and $\mathrm{CoS}_{2}$ ) suffer from poor cyclic stability due to severe volume expansion during lithiation/delithiation. As the most studied TMD, MoS 2 possesses weak interlayer bonding via van der Waals interactions that can allow for $\mathrm{Li}$ insertion/extraction with less severe volume expansion, thus it has been exploited as anode material for LIBs. However, due to its intrinsically low electrical conductivity and structural distortions during battery cycling via conversion reactions, the practical use of $\mathrm{MoS}_{2}$ is still hindered by its inferior rate performance and poor cyclic stability. 
Recent research efforts have focused on the preparation of 2D TMDs with varying electrical properties to enhance their electrochemical performance, either in their pristine 2D forms, designing heterostructures with other 2D materials or as composited with other electrical conductive materials (e.g. carbon nanotube and graphene). Here, the lithium-ion storage mechanism is still poorly understood, with experimentally observed specific capacities of $\mathrm{MoS}_{2}$ and $\mathrm{MoS}_{2}$ based composite materials often exceeding the theoretical expectations (167 mAh $\mathrm{g}^{-1}$ for the bulk $\mathrm{MoS}_{2}$ and $334 \mathrm{mAh} \mathrm{g}^{-1}$ for MoS 2 nanolayers). Recently several possible reaction mechanisms for $\mathrm{MoS}_{2}$-based anodes were reported which included: (1) Mo nanoparticles remain electrochemically inert, each sulfur center has pyramidal bonding and is connected to three Mo centers, and the alkali sulfides can be oxidized to generate $S$ atoms;[27] (2) the 1T phase $\mathrm{MoS}_{2}$ can dynamically expand to accommodate $\mathrm{Li}^{+}$, the enhanced capacity relies on the formation of the charge layer containing cations at the interface between the metal and lithium;[28] (3) the extra capacity is mainly attributed to $\mathrm{Mo} / \mathrm{Li}_{\mathrm{x}}$ which is formed from the reversible reactions with generated Mo atoms and $\mathrm{Li}$. The recent lithium-storage mechanism for the increasing capacity is proposed in Figure 4. A large amount of $\mathrm{Li}^{+}$can be accommodated because of the atomic scale Mo precipitates in the $\mathrm{Li}_{2} \mathrm{~S}$ matrix, thus enabling the reversible $\mathrm{Mo} \rightarrow \mathrm{Li}_{\mathrm{x}} \mathrm{Mo} \rightarrow \mathrm{Mo} \rightarrow 1 \mathrm{~T}-\mathrm{MoS}_{2}$ reaction during repeated charging/discharging, which was also accountable for the outstanding cyclic stability;[29]. Recent research has also indicated that the intercalation of lithium at the level of individual atomic interfaces of dissimilar van der Waals layers (Figure 4). Compared to $\mathrm{MoX}_{2} / \mathrm{MoX}_{2}\left(\mathrm{MoX}_{2} ; \mathrm{X}=\mathrm{S}\right.$, Se) homo interfaces, a more than tenfold greater accumulation of charge in $\mathrm{MoX}_{2}$ can be found in the formation of van der Waals hetero interfaces between $\mathrm{MoX}_{2} / \mathrm{MoX}_{2}$ and graphene, enforcing a more negative intercalation potential (at least $0.5 \mathrm{~V}$ ) than the bulk $\mathrm{MoX}_{2}$, opening new pathways to better control the charge densities in two-dimensional materials.[30]
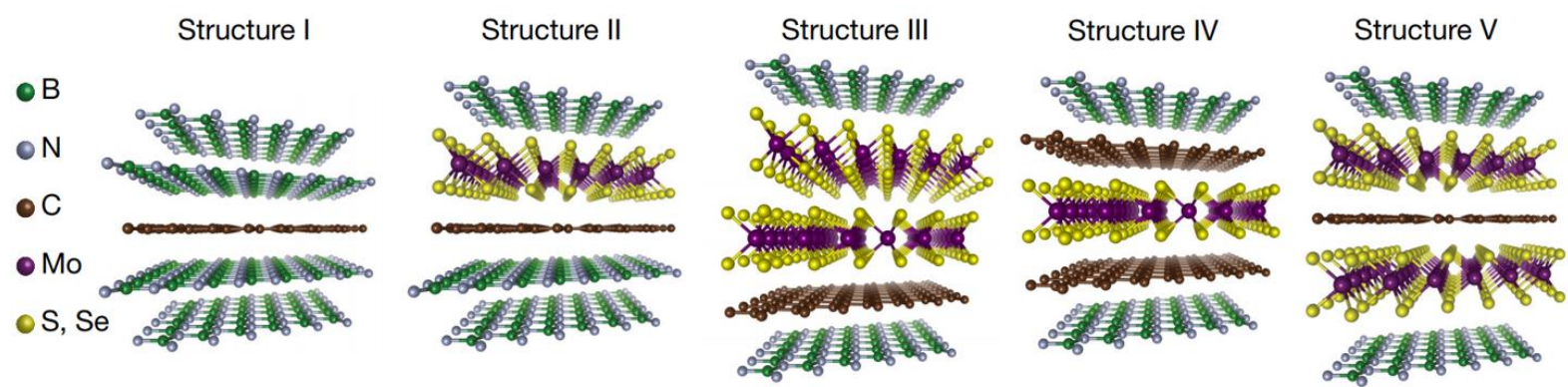

Figure 4. Van der Waals heterostructures for lithium intercalation [30].

2D $\mathrm{MoS}_{2}$ nanosheets/nanoflakes have the advantages of large specific surface area and increased interlayer distance, resulting in a shortened $\mathrm{Li}^{+}$diffusion pathway, fast electron transport and increased sites for ion storage. Furthermore, the unique features of the 2D nanoflakes can be largely maintained when the 2D nanoflakes are assembled into 3D nanostructured layered hierarchical structures, and the restacking of 2D nanosheets can be effectively inhibited. This type of 2D based 3D hierarchical structure is so far applicable to many TMDs with various shapes, such as hollow tubular, hollow box, aerogel, micro-spheres and hollow nanospheres of $\mathrm{MoS}_{2}$.

In a recent report, a well-defined hierarchical 3D column-like $\mathrm{MoS}_{2}$ superstructures with edgeterminated 2D $\mathrm{MoS}_{2}$ nanosheets were prepared via a solvothermal approach. This superstructure contains edge-terminated 2D MoS 2 nanosheets with the advantage of having 3D accessible sites, maximized edges, and favourable interlayer distances. Such $\mathrm{MoS}_{2}$ structures were shown to achieve a high reversible specific capacity of $840 \mathrm{mAh} \mathrm{g}^{-1}$ at 200 
$\mathrm{mA} \mathrm{g}^{-1}$, impressive cyclic stability of up to 500 cycles, and outstanding rate performance as an anode in a LIB [31].

\section{c. Transition Metal Carbides/Nitrides (MXenes)}

MXenes, which are a new family of 2D exfoliated early transition metal carbides/nitrides materials, were firstly developed by Gogotsi co-workers via selective etching of the A-element from MAX phase precursors (layered ternary carbides and carbonitrides), where $M$ is an early transition metal, $A$ is an element from mainly the IIIA and IVA group elements, and X is carbon and/or nitrogen. The MXenes have been reported to be electrical conductive, and $\mathrm{Li}^{+}$ions are predicted to diffuse fast on their surface, leading to a large capacity and high rate capability, thus triggering a large amount of work exploiting them as anode materials in LIBs. Following the positive results from the use of bare MXenes of $\mathrm{Ti}_{3} \mathrm{C}_{2} \mathrm{~T}_{\mathrm{x}}$ and $\mathrm{Ti}_{2} \mathrm{CT}_{\mathrm{x}}$ as anodes, new MXenes and their composites have also been developed as $\mathrm{Li}^{+}$intercalation hosts, such as $\mathrm{Mo}_{2} \mathrm{Ti}_{2} \mathrm{C}_{2} \mathrm{~T}_{x}, \mathrm{Cr}_{2} \mathrm{TiC}_{\mathrm{x}} \mathrm{T}_{x}, \mathrm{Nb}_{4} \mathrm{C}_{3} \mathrm{~T}_{\mathrm{x}}$, and their composites with TMOs and TMDs. Currently HF and HF-containing etchants have been widely used for the preparation of various MXenes. However, the surfaces of the prepared MXenes have several functional groups (such as $-\mathrm{F}$, $\mathrm{OH}$ and $=\mathrm{O}$ ) while the defects in MXenes can irreversibly react with cations and lower the observed coulombic efficiency. Therefore, mild synthesis conditions should be taken into consideration in battery applications. For example, a larger lateral size and high electrical conductivity can be obtained if the HF concentration is low, short etching time, and with minimum structural damages caused by sonication.

Recently, the etching of $\mathrm{Ti}_{3} \mathrm{AlC}_{2}$ in the organic base tetramethylammonium hydroxide (TMAOH) has been successfully demonstrated, but this still requires some diluted HF to remove the surface oxidation layer of the MAX in advance [32]. A recent report provides a safe and fluorine-free process to obtain MXenes with only $-\mathrm{OH}$ and $=\mathrm{O}$ surface terminations by using $\mathrm{NaOH}$ [33]. Nevertheless, the available precursors were initially limited to only Al-based MAX because pure HF cannot break the $\mathrm{Ti}$-Si bonds of $\mathrm{Ti}_{3} \mathrm{SiC}_{2}$ [34]. An oxidant-assisted selective etching strategy was then successfully developed to produce $\mathrm{Ti}_{3} \mathrm{C}_{2} \mathrm{MXene}$ from $\mathrm{Ti}_{3} \mathrm{SiC}_{2}$. This new synthetic method is significantly important to widen the range of MXenes.

As for their further application in LIBs, similar to other 2D materials, MXene sheets still suffer from restacking problems. $\mathrm{Ti}_{3} \mathrm{C}_{2} \mathrm{~T}_{\mathrm{x}}$ is regarded as an ideal host for TMOs to construct advanced LIB anodes. As a successful example, MXene layers can provide excellent electrical conductivity, and $\mathrm{SnO}_{2}$ can prevent the restacking of the layered MXenes, delivering good electrochemical performance. As for morphological engineering, Kajiyama et al. reported a $\mathrm{Ti}_{2} \mathrm{CT}_{\times}$MXene with steric chloride terminations and increased interlayer spacing, resulting in enhanced electrochemical performances of LIBs.[35] 3D hollow structures are also good design for MXenes to achieve high performance. As shown in Figure 5, Zhao et al. fabricated 2D MXene flakes into hollow spheres and 3D architectures via a sacrificial template approach, obtaining free-standing, flexible, and highly conductive 3D macroporous MXene films.[36] Recently, vertically aligned MXene sheets have been prepared by mechanical shearing of a discotic MXene lamellar liquid crystal, enabling the possibility to prepare thick vertically aligned MXenes with high rate charging/discharging cycles.[37] 

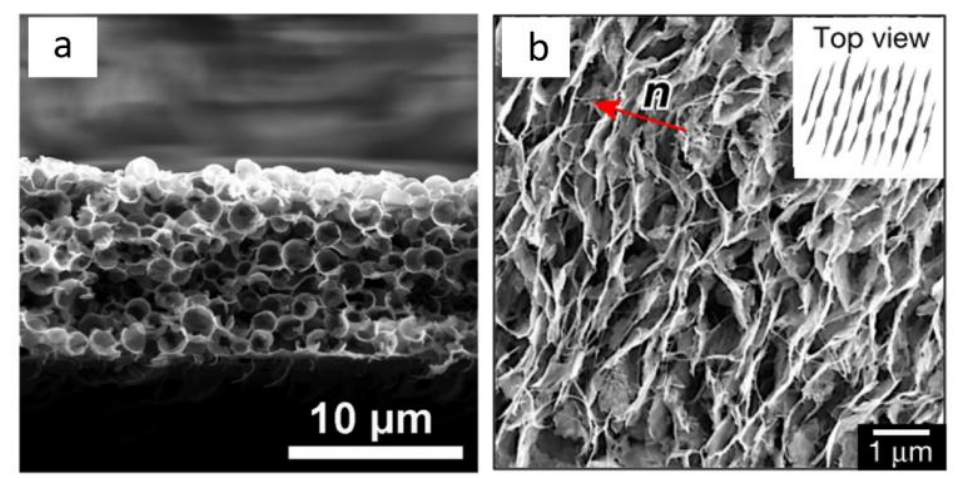

Figure 5. a) Cross-sectional SEM image of the 3D macroporous V2CTx film.[36] b) Top view of SEM image of the MXene lamellar liquid crystal.[37]

\section{Outlook:}

To satisfy the practical requirements of real-world batteries, the specific capacity and cycle life of 2D MTMOs needs to be improved. The controllable and scalable preparation of the structural MTMOs is still required, such as hollow, core-shell, and yolk-core structures. Doping of MTMOs with ions and surface modification and coating on MTMOs is proposed to reduce the undesired side reactions and obtain improved electrochemical performances of MTMOs. Further efforts should be focused on effective synthesis strategies to prepare pure metallic TMDs and their 3D architectures. 3D structural design and delicate controlled preparation are still challenging, the exploration of 3D TMD architectures based on other types of TMDs is needed (such as $\mathrm{VS}_{2}, \mathrm{NbS}_{2}, \mathrm{ReS}_{2}$, and MoTe $\mathrm{M}_{2}$ ). 3D TMD architectures can be more conductive to ion diffusion due to vertical ion pathways provided by these architectures. More work is required to facilitate the scale-up synthesis routes of various MXenes. Besides, the $\mathrm{M}_{2} \mathrm{C}$ type of MXenes (with light transition metals and no functional groups or $=0$ terminations) are potential $\mathrm{MXene}$ anode materials. For example, $\mathrm{V}_{2} \mathrm{C}$ has high theoretical capacitance of $940 \mathrm{mAh} \mathrm{g}^{-1}$, while $\mathrm{Ti}_{3} \mathrm{C}_{2}$ is $447.8 \mathrm{mAh} \mathrm{g}^{-1}$.

\section{Electrolytes}

The key to the huge commercial success of LIBs lies in the fact that the technology uses a non-aqueous ion conductor as electrolyte, stable up to $\sim 4.5 \mathrm{~V}$, instead water based electrolytes used in Li ion predecessors which typically withstand $\sim 1 \mathrm{~V}$. As energy density is the product of cell voltage and capacity, Li ion cells with a nominal voltage of $3.6 \mathrm{~V}$ (chemistry based on graphite and $\mathrm{LiCoO}_{2}$ cells) can deliver up to $150 \mathrm{Wh} / \mathrm{kg}$, whilst a lead-acid battery with a nominal $1 \mathrm{~V}$ delivers about 30-40 Wh/kg (see Figure 6a). The key deference between aqueous and non-aqueous electrolytes in batteries is depicted in Figure $6 \mathrm{~b}$ using frontier molecular orbitals [38]. The energy gap $\left(E_{g}\right)$ between the lowest unoccupied molecular orbital (LUMO) and the highest occupied molecular orbital (HOMO) is wide for non-aqueous electrolytes, meaning that their electrochemical stability window is much higher than water based electrolytes. This allows for the combination of most negative and most positive electrodes, which in turn maximises cell voltage $V_{O C}=\left(\mu L i_{(c)}-\mu L i_{(a)}\right) / n F$, whereas for waterbased electrolytes, the stability window is narrower due to water decomposing into gaseous products $\left(\mathrm{H}_{2}\right.$ and $\left.\mathrm{O}_{2}\right)$ at lower potentials. 

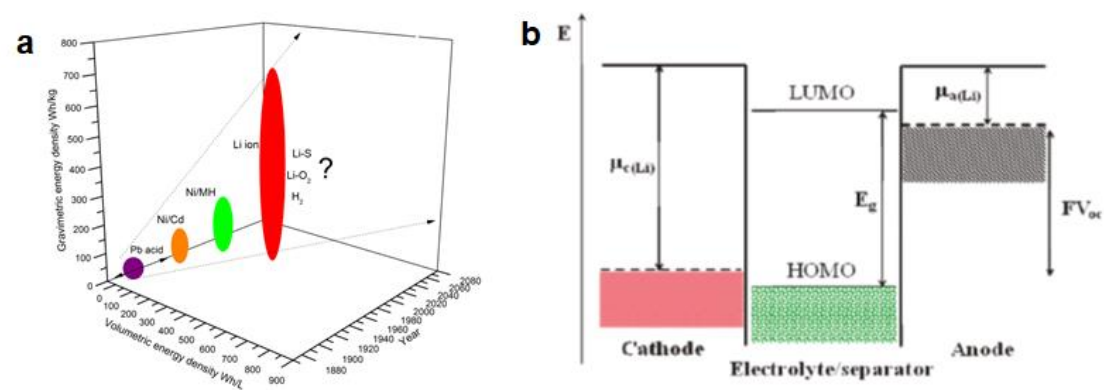

Figure 6. a) Graph comparing gravimetric and volumetric energy densities offered by Li ion technology; b) Energy level diagram [38] showing electrochemical band gap of non-aqueous compared to water based electrolytes which enables the coupling of electrodes with wide electrochemical potentials leading to higher cell voltage.

Traditionally an electrolyte is water containing solution with dissolved inorganic salts, where dissociated anions and cations act as charge carriers, exhibiting ionic conductivity across the medium. Similarly, non-aqueous electrolytes are basically organic solvents (with high dielectric constants) containing dissolved inorganic salts too. In typical LIBs [39], the two electrodes (anode and cathode) are electronically isolated by a separator soaked in the electrolyte (Figure 7a). When recharging, Li ions move out from cathode towards anode via separator and electrolyte, where Li ions are mostly surrounded by solvent molecules as they migrate across electrode/electrolyte interface. When Li ions arrive at the anode, they begin to be intercalated into graphite anode (between the graphitic layers based on the $\mathrm{LiC}_{6}$ stoichiometry) and electrolyte moieties undergo reductive decomposition forming a thin polymer layer around battery active particles and this layer is termed as solid electrolyte interphase (SEI),[40] which in fact passivates the battery active particles (Figure 7b). Thus, electrolytes not only serve as a finite reservoir to compensate for $\mathrm{Li}$ ions that are irreversibly consumed over battery charge/discharge cycles but also protect the electrode particles by preventing additional parasitic reactions from taking place. However, if the SEI layer is not stable in the event of active particles cracking and disintegrating as a result of stress build up, a new layer needs to be formed, therefore it is important that the SEI should be as stable as well as the mechanical integrity of the active particles. Figure 7c-d shows the formation of SEI $[41,42]$ on battery active particles as a result of $\mathrm{Li}$ ion intercalation and de-intercalation over battery charge-discharge cycles and this layer can be considered as inorganic-organic composites.

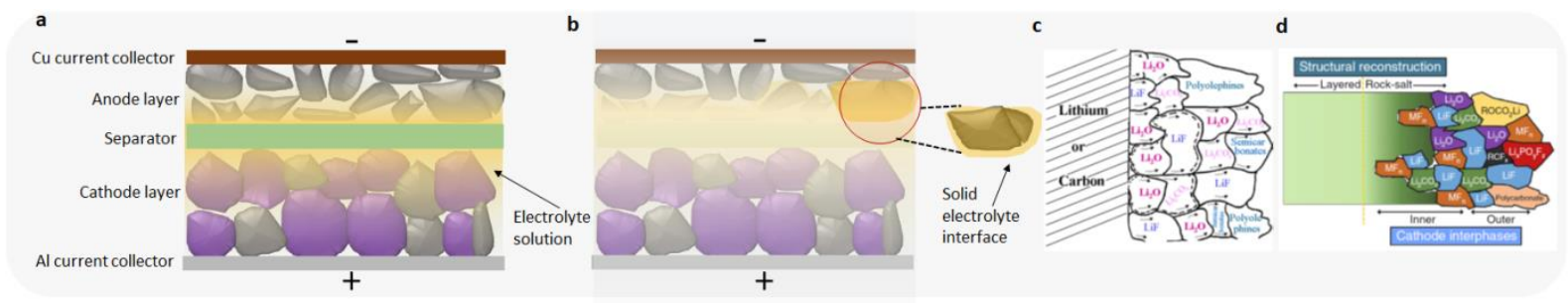

Figure 7. Schematic representation of $\mathrm{Li}$ ion batteries a) before battery cycling, electrolyte solution filling up electrode pores; b) after cycling the formation of solid electrolyte interface on electrode particles; c-d) schematic showing the chemical make-up of SEI on anode and layers that grow on cathode.[41,42]

a Pivotal role of electrolyte in Li ion batteries: The primary role of the electrolyte is to provide ionic conductivity across electrodes for battery operation, to which a bare minimum value should be in the range of $1 \times 10^{-4}$ to $1 \times 10^{-3} \mathrm{~S} / \mathrm{cm},[43,44]$. To avoid risks of fire and 


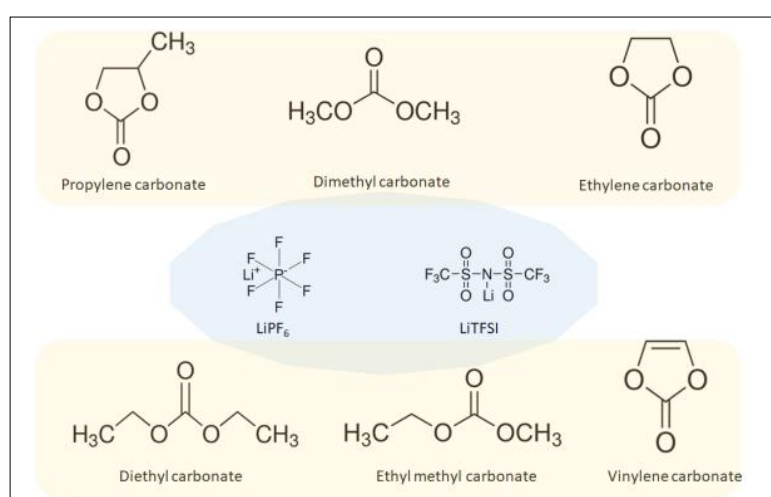

Figure 8. Carbonate based electrolytes and Li salts used in lithium ion batteries.

explosion at high current charge/discharge cycles, electrolytes must be non-flammable. Electrolytes should wet battery active particles across the electrodes and fill electrode pores to enable the access of electrolyte to battery active particles, so as to promote a facile $\mathrm{Li}$ exchange between electrolyte and battery active particles. The electrolytes must be chemically stable. As discussed earlier, the electrochemical potential window of the electrolyte should be as wide as possible in order to combine electrodes with a wide range of electrochemical potentials vs. $\mathrm{Li}^{2} \mathrm{Li}^{+}$. Finally, electrolytes should be sufficiently inert, without interfering with electrodes and battery components, thus avoiding deleterious side reactions.

b. Lithium salts in carbonate based electrolytes and additives: This family of electrolytes has been in use for more than two decades since the commercialisation of LIBs in 1991 by the Sony Corporation. Carbonate [45] based electrolytes (Figure 8) are high dielectric solvents which effectively dissociate inorganic $\mathrm{Li}$ salts, e.g. hexafluorophosphate $\mathrm{LiFP}_{6}\left(\mathrm{LiPF}_{6}\right)$ or lithium bis(trifluoromethanesulfonyl)imide (LiTFSI), providing ionic conductivity in range of $1 \times 10^{-4}$ to $1 \times 10^{-3} \mathrm{~S} / \mathrm{cm}$ with a high degree of wettability, which enables battery charge/discharge cycles with acceptable capacities and columbic efficiencies over a few hundreds of cycles before significant performance decay can be observed. Intensive research over the years adds to the increasing body of evidence suggesting that these electrolytes are not the best, and their continued deployment in next-generation batteries is doubtful due to their flammability, in addition to their toxicity and high reactivity. This may be linked to the often reported battery fire and explosion in commercial devices where LIBs were found to undergo thermal runaway (smoke, fire even explosion mostly during recharge), which seriously undermines the viability of carbonate electrolytes. However, to improve the safety and to prevent degradation of $\mathrm{Li}$ ion electrodes in carbonate based electrolytes, certain electrolyte additives are introduced in order to tweak SEI properties by improving electrolyte ability to passivate more strongly active particles and even metal surfaces. In many cases, this proves to be beneficial to some extent as electrolyte additives promote the formation of more

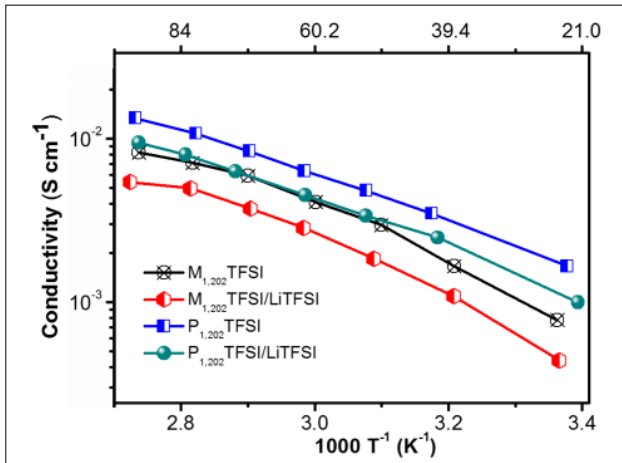

Figure 9. Ionic conductivities of ether-functionalized morpholinium- and piperidiniumbased ionic liquids as Electrolyte.[48] compact and stable SEI, resulting in improved electrochemical performance. Some examples for additives include vinylene carbonate, 3-fluoro-1,3-propane sultone, fluoroethylene carbonate, lithium difluoro(oxalato) borate ( $\mathrm{LiDFOB})$, lithium nitrate $\left(\mathrm{LiNO}_{3}\right)$, lithium carbonate $\left(\mathrm{LiCO}_{3}\right)$ etc.

c. Lithium salts in ether based electrolytes and lonic Liquids: As an alternative to Li saltcarbonates, Li salt-ether based electrolytes have been introduced as they exhibit improved electrochemical properties, high chemical stability and low-cost. For example dioxolane DOL/1,2-dimethoxyethane (DME) electrolytes tended to impart less electrode polarisation and they could pair well with conversion type electrodes, leading to high capacity and rate- 
capability when benchmarked against carbonate-based electrolytes (EC/DEC/DMC)[46] in the case of $\mathrm{CuFeS}_{2}$ and $\mathrm{CuS}_{2}$ anodes for LIBs [47]. Such observation suggests that Li-ether based electrolytes can play a significant role not only in the next-generation LIBs but in metal, metalair and sulphur based batteries that can offer energy densities many times higher than Li ion. Ether-functionalized morpholinium and piperidinium-based ionic liquids as electrolytes was proposed by Scrosati and co-workers, with improved ionic conductivities (Figure 9). These electrolytes with $\mathrm{Li}$ salts improved anodic stability up to $5 \mathrm{~V}$ vs. $\mathrm{Li}^{2} \mathrm{Li}^{+}$and facilitated stable SEI layers. When tested in $\mathrm{Li}$ and $\mathrm{Li}$-ion cells using a LFP cathode and $\mathrm{Sn} / \mathrm{C}$ anode, the cells displayed stable charge/discharge profiles, which in combination with carbonates offered a $\sim 100 \%$ coulombic efficiency [48], pointing out that the mixtures of electrolytes often tend to yield good electrochemical performance. Tetra ethylene glycol dimethylether (TEGDME) with lithium bis(oxalate) borate (LiBOB) salt has also been investigated as an electrolyte which exhibited a conductivity ranging between $1 \times 10^{-3}$ and $1 \times 10^{-2} \mathrm{~S} \mathrm{~cm}^{-1}$ and thermal stability as high as $180^{\circ} \mathrm{C}$ and electrochemical stability window ( 4.6 anodic and $\sim 1.5 \mathrm{~V}$ cathodic). With LFP electrodes the cells showed good cycling stability and even with $\mathrm{Sn}-\mathrm{C}$, the cells using this electrolyte did not show significant capacity decay [49]. Yamada and co-workers have reported an important observation that using a 1,2-dimethoxyethane (DME) electrolyte solution containing $\sim 3.6 \mathrm{~mol} \mathrm{dm}^{-3}$ of $\mathrm{LiN}\left(\mathrm{SO}_{2} \mathrm{~F}\right)_{2}$ (lithium bis(fluorosulfonyl) amide, LiFSA), which is highly concentrated salt solution (Figure 10), an ionic conductivity up to $7.2 \mathrm{mS} \mathrm{cm}^{-1}$ could be achieved. This enabled fast charging of graphite anodes at $2 \mathrm{C}$ without Li plating (which often leads to Li dendrites), as this is very difficult to perform in Li-carbonate based electrolytes. Analysing the voltage profiles of cells containing DME/containing LiFSA salt, the electrode polarisation was found to be lower than carbonate electrolyte with $\mathrm{LiPF}_{6}$. The $\mathrm{Li}^{+}$intercalation was reversible in such highly concentrated electrolyte (Figure 10b) and this can guide the design of high-rate performance electrolytes other than carbonates[50] .

d. Solid polymer based electrodes (SPE) This class of electrolytes is considered to be

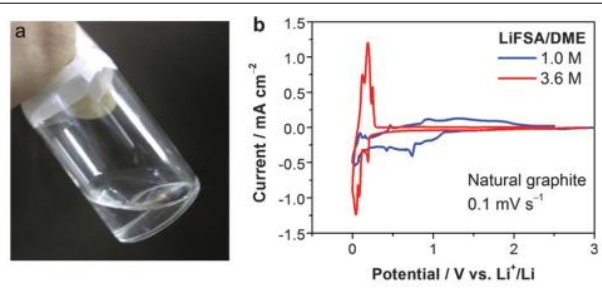

Figure 10. Concentrated electrolyte with Li salts and cyclic voltammetry curves of $\mathrm{Li}$ interaction in carbon with two different salt concentration.[50] advantageous over liquid ones because SPEs reduce combustibility, avoid leakage and improve compactness of devices. However one main drawback of SPEs is that they suffer from reduced ionic conductivities $\left(1 \times 10^{-7}\right.$ to $1 \times 10^{-9} \mathrm{~S} / \mathrm{cm}$ at room temperature), which is detrimental to battery performance, even in low-rate charge/discharge cycles. Cui and coworkers have demonstrated that by using nanowires in polymers as composites [51], the ionic conductivities could be increased considerably. By employing composite of yttrium oxide $\left(\mathrm{Y}_{2} \mathrm{O}_{3}\right)$ and zirconium oxide $\left(\mathrm{ZrO}_{2}\right)$ nanowires with polyacrylonitrile (PAN) and $\mathrm{Li}$ perchlorate in dimethylformamide (DMF), a more continuous ion conducting pathways in flexible SPEs was shown (Figure 11), with a high conductivity of $1.07 \times 10^{-5} \mathrm{~S} \mathrm{~cm}^{-1}$ at $30^{\circ} \mathrm{C}$, due to surface vacancies on these oxides aiding fast dissociation of $\mathrm{Li}$ salts. Such an approach is highly conducive to further improve both electrochemical and mechanical stability of electrolytes. They further extended this concept by aligning polymers chains with nanowire like structures [52], showing significant improvements in terms of ionic conductivity almost reaching $6.05 \mathrm{x}$ $10^{-5} \mathrm{~S} \mathrm{~cm}^{-1}$ at $30^{\circ} \mathrm{C}$ due to low activation energies for ion migration. They also pointed out the 
enhanced stability of these electrolytes was due to the addition of nanowires that offer fast ion conducting pathways, which minimises crossing junctions on the surface of aligned nanowires.

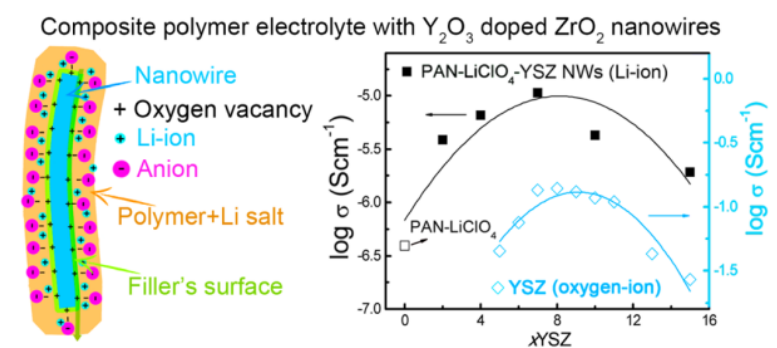

Figure 11. Electrolyte design with nanowires for improved ionic conductivity.[51]
On the other hand, Goodenough and coworkers took a slightly different approach to further advance SPE into CPE (Figure 12), by incorporating ceramic fillers, which formed a 3D continuously networked structure that consisted of a lanthanum lithium titanate (LLTO) framework and offered conductivity $\sim 8.8 \times 10^{-5} \mathrm{~S} \mathrm{~cm}^{-1}$ at room temperature [53] which was attributed to the more percolated structure offering continuous

ion hopping sites. Such an approach effectively mitigates the issue of filler aggregation, which is a typical bottleneck often encountered in SPE fabrication, leading to diminished ion conductivity.

e. Solid electrolytes: Although liquid based electrolytes offered several improvements in terms of ionic conductivity, wettability and electrolyte accessibility, safety concerns are alarmingly high because of their combustibility and leakage. SPEs, instead, partly overcomes these limitations but still suffer from low ionic conductivities and parasitic reactions leading to poor battery performance. This intensifies research into solid electrolytes to develop all-solid-state batteries, which can potentially overcome the problem of battery thermal runaway (battery fire and

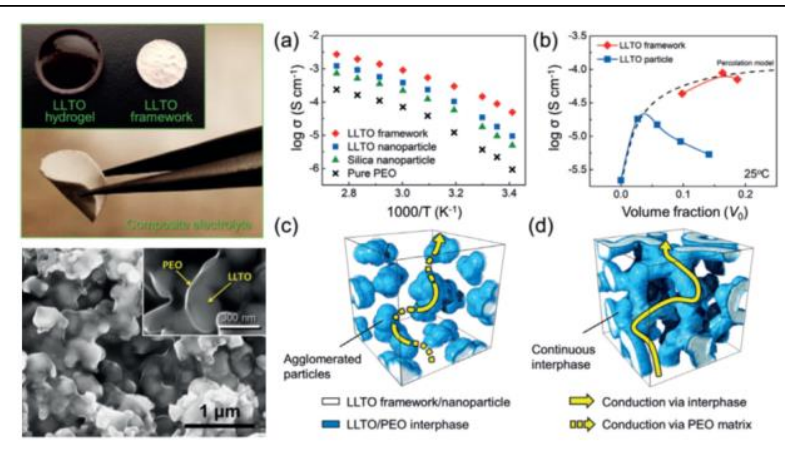

Figure 12. CPE based electrolytes and their ionic conductivities and conductive pathways with agglomerated nanoparticles and 3D continuous matrix.[53]

explosion) and improve the shelf-life of batteries by effectively mitigating deleterious parasitic reactions. However, the ionic conductivity and Li exchange at solid-solid interface are a critical issue. For example, Wagemaker and co-workers have investigated by employing ${ }^{7} \mathrm{Li}$ NMR and DFT molecular dynamics simulations, the $\mathrm{Li}$ ion conduction in argyrodite $\left(\mathrm{Li}_{6} \mathrm{PS}{ }_{5} \mathrm{Cl}\right)$ that is known for high $\mathrm{Li}$ ion conductivity in its bulk form (Figure 13). They found that the grain boundaries of $\mathrm{Li}_{6} \mathrm{PS}{ }_{5} \mathrm{Cl}$ play a significant role in $\mathrm{Li}$ ion conductivity such that the $\mathrm{Li}$ transport the across $\mathrm{Li}_{6} \mathrm{PS}_{5} \mathrm{Cl}-\mathrm{L}_{2} \mathrm{~S}$ interface is a major limiting factor in improving the performance of all solid state batteries [54]. Later on, in a follow-up investigation into $\mathrm{Li}_{6} \mathrm{PS}{ }_{5} \mathrm{Cl}$ and $\mathrm{Li}_{6} \mathrm{PS}{ }_{5} \mathrm{Br}$ via detailed DFT and molecular dynamics analysis, they found that the presence of halogen atoms is of crucial importance as they influence the degree of $\mathrm{Li}$ ion conductivity. This reveals that by altering the position of the halogen ion distribution, Li ion conductivity can be increased by 2-3 times [55]. Garnet-type compounds are another class of interesting solid electrolytes, for example, Guo and co-workers showed that $\mathrm{Li}_{6.20} \mathrm{Ga}_{0.30} \mathrm{La}_{2.95} \mathrm{Rb}_{0.05} \mathrm{Zr}_{2} \mathrm{O}_{12}$ electrolytes [56], by doping $\mathrm{Rb}$ atoms in $\mathrm{Li}{ }_{6.10} \mathrm{Ga}_{0.30} \mathrm{La}_{3} \mathrm{Zr}_{2} \mathrm{O}_{12}$, the ionic conductivity can be improved (1.62 m S $\mathrm{cm}^{-1}$ at room temperature). This reduced the interfacial resistance in electrodes containing $\mathrm{LiFePO}_{4}$ and $\mathrm{Li}\left(\mathrm{CF}_{3} \mathrm{SO}_{2}\right)_{2} \mathrm{~N}$ (an electrolytic salt), resulting in high discharge capacity and cycling stability at $60^{\circ} \mathrm{C}$. Kanno and co-workers have reported sulfide based superionic 


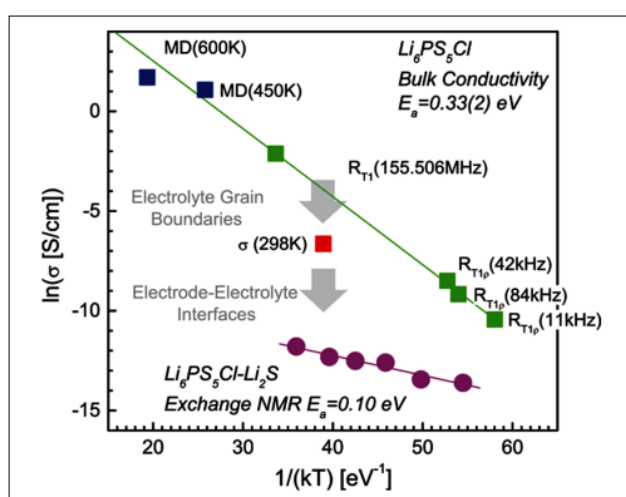

Figure 13: $\mathrm{Li}$ ion conductivity in $\mathrm{Li}_{6} \mathrm{PS}_{5} \mathrm{Cl}$ and $\mathrm{Li}_{6} \mathrm{PS}_{5} \mathrm{Cl}-\mathrm{Li}_{2} \mathrm{~S}$ from NMR and DFT analysis.[54]

conductors, in particular, an ionic conductivity of 25 $\mathrm{mS} \mathrm{cm}{ }^{-1}$ for $\mathrm{Li}_{9.54} \mathrm{Si}_{1.74} \mathrm{P}_{1.44} \mathrm{~S}_{11.7} \mathrm{Cl}_{0.3}$, as shown in Figure 14 , enabling the development of lithium superionic conductors [57]. Using this electrolyte they have demonstrated that the specific power of cells (a chemistry based on $\mathrm{LiCoO}_{2}$ and $\mathrm{Li}_{4} \mathrm{Ti}_{5} \mathrm{O}_{12}$ ) is far superior compared with cells containing liquid electrolytes. Besides this, with excellent electrochemical stability, this family of electrolytes enables ultrafast charging and battery operation at 100 ${ }^{\circ} \mathrm{C}$ (at a rate of $18 \mathrm{C}$ ), under which the conventional LIBs may not be able to function.

f. Other interesting developments: To improve Li ion battery safety, Yamada and co-workers further found that Li salts in extreme concentration can still reach commercial level conductivities $(1.12 \mathrm{mS}$ $\mathrm{cm}^{-1}$ ) despite their high viscosity in a poly carbonated solvent (LiFSA/DMC), offering competitive rate capabilities [58]. This was attributed to the formation of a 3D network of anions and solvent moieties strongly bonded to $\mathrm{Li}^{+}$and which prevented degradation of the aluminium collector and dissolution of metal cations in cathode particles. This allows for a $5 \mathrm{~V}$ battery (based on $\mathrm{LiNi}_{0.5} \mathrm{Mn}_{1.5} \mathrm{O}_{4}$ and graphite) with improved rate capability. From flame tests, it was shown that the highly concentred electrolytes exhibited reduced flammability compared to commercial electrolytes (much diluted ones). They further demonstrated that by using a concentrated electrolyte [59] with a commercial flame-retardant solvent, trimethyl phosphate (TMP), cycling of conventional graphite based anodes over 1000 times with almost no discernible battery degradation could be realised, which was attributed to the ability of highly concentrated electrolytes (5.3 M LiFSA/TMP) in producing a more salt based SEl. Such a layer tended to be more uniform and robust with improved

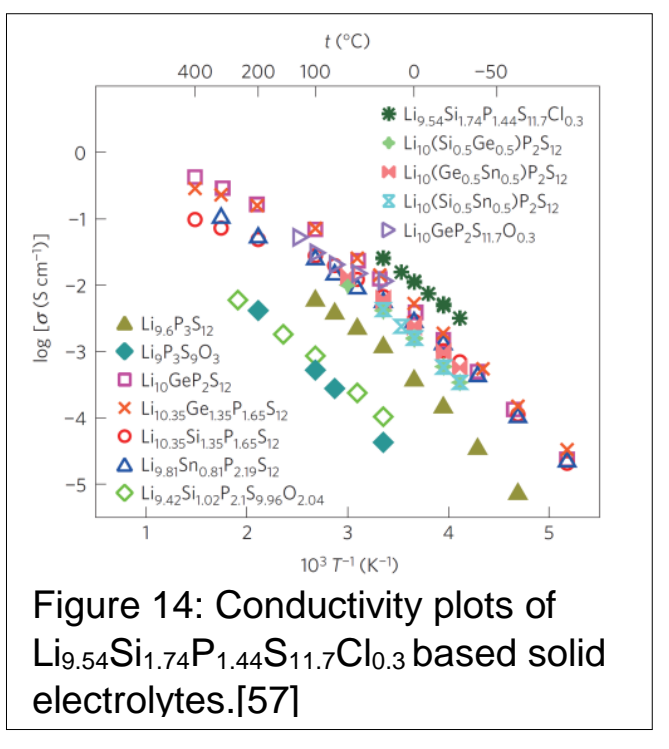
passivating ability. Similarly, salt in water by Kang and co-workers made a significant contribution that aqueous electrolytes can have an extended electrochemical stability window (from $\sim 1.2 \quad \mathrm{~V}$ to $\sim 3.0 \mathrm{~V}$ ). By dissolving $\mathrm{Li}$ salts such as lithium bis(trifluoromethanesulfonyl)imide (LiTFSI) to an extent of $21 \mathrm{M}$, an interphase containing lithium fluoride (LiF) via TFSI reduction could be achieved at electrode/electrolyte, which not only expanded the potential window to $\sim 3.0 \mathrm{~V}$ (from typical $1.2 \mathrm{~V}$ ) [60] but allowed full Li ion cells (consisting of with $\mathrm{LiMn}_{2} \mathrm{O}_{4}$ and $\mathrm{Mo}_{6} \mathrm{~S}_{8}$ ) to have an open circuit voltage of $2.3 \mathrm{~V}$.

Outlook: Despite the many developments in formulation and preparation of electrolytes for LIBs, battery performance requirement for heavy duty applications such as electric vehicles and power tools is still far from reality due to rapid performance decay, thermal runway, weight and cost. As every new electrolyte proposed and tested to date has advantages as well as disadvantages, therefore a trade-off is inevitable in terms of safety, energy/power density and package. However, many problems that hindered the progress of $\mathrm{Li}$ ion cells for low power application, because of the limitations imposed by electrolytes, have been reasonably circumvented. While these results are encouraging, developing electrolytes for high/low 
temperature and high-voltage batteries that can offer desired energy/power, weight, longevity and cost effectiveness remains still as a great challenge.

\section{Concluding Remarks}

Following the revolution in consumer electronics enabled by LIBs, internal combustion engines that run on gasoline are currently being replaced by electric engines powered by LIB technologies. In LIBs, cathodes mostly dictate the overall battery performance, and the initially employed LCO cathodes are becoming obsolete owing to their toxicity and low capacity and safety hazards. Lithiated metal phosphate cathodes demonstrate enhanced stability, in particular LFP with carbon coating is promising but with limited energy. Mixed cation layers oxides are now the mainstream of electrodes as they improve energy density but issues such as mechanical/chemical stability and voltage decay are still main concerns. Mitigation measures such coating of ionic compounds or doping of cations can be of some help but comes at the expense of either capacity or manufacturing issues. As far the anodes are concerned, it has been nearly three decades now since carbon based anodes were introduced in LIBs. Alternative anodes are urgently required because of the limited capacity of graphite and the issue of Li dendrites with graphite electrodes. Metal oxides can be a good alternative in terms of energy and rate performance but the issues such as volume expansion, voltage hysteresis, higher operating voltages and parasitic reactions associated with metal oxides offset their merits. Following the discovery of graphene, many layered materials gained traction as anodes, most notably metal chalcogenides and MXenes. Although they demonstrated better performance than metal oxide, many barriers such as poor mechanical integrity and inconsistent performance appear to limit further progress. Finally, electrolytes are a crucial battery component as they serve as Li reservoir for maintaining the cyclable Li over repeated charge/discharge cycles. The conventional polycarbonates, despite their use over many years, are being modified if not completely replaced. Electrolyte additives are being increasingly used as they help form better solid electrolyte interface leading to improved cycling performance. Although solid-state electrolytes can overcome the problem of safety hazards, the electrochemical kinetics in terms of Li exchange between solid- to-solid interface carries heavy energy penalty than solid-liquid interface. Solid polymer or gel electrolytes can be interesting for flexible electrodes but ion diffusion and stability over long battery cycling is still a concern. Water based electrolytes have been revived by adopting supersaturated salt concentration and the voltage range is almost doubled.

In the summary, it is clear that a trade-off is inevitable part of the current battery performance in terms of energy/power as most of the materials or combinations tend to fail, which undoubtedly calls for more concerted efforts in materials design and manufacturing and judicious choice of anode/cathode/electrolyte for optimally benefiting from LIB technology.

\section{Acknowledgement}

$X L$ and BW thank the EPSRC energy storage for low carbon grids project (EP/K002252/1), the EPSRC Joint UK - India Clean Energy Centre (JUICE) (EP/P003605/1), the EPSRC Multi - Scale Modelling project (EP/S003053/1), and the Innovate UK for Advanced Battery Lifetime Extension (ABLE) project. HW would like to thank the EPSRC for funding under EP/S000933/1. The Royal Society is acknowledged for an URF (of CG).

\section{Abbreviations and Acronyms}

2D Two-dimensional

3D Three-dimensional

TMOs Transition metal oxides 
TMDs Transition metal dichalcogenides

MTMDs Mixed Transition metal dichalcogenides

MXenes Transition metal carbides/nitrides

\section{References}

[1] N. Nitta, F. Wu, J.T. Lee, G. Yushin, Li-ion battery materials: present and future, Mater. Today. 18 (2015) 252-264. doi:10.1016/J.MATTOD.2014.10.040.

[2] M.D. Radin, S. Hy, M. Sina, C. Fang, H. Liu, J. Vinckeviciute, M. Zhang, M.S. Whittingham, Y.S. Meng, A. Van der Ven, Narrowing the Gap between Theoretical and Practical Capacities in Li-lon Layered Oxide Cathode Materials, Adv. Energy Mater. 7 (2017) 1602888. doi:10.1002/aenm.201602888.

[3] A. Manthiram, B. Song, W. Li, A perspective on nickel-rich layered oxide cathodes for lithium-ion batteries, Energy Storage Mater. 6 (2017) 125-139.

doi:10.1016/j.ensm.2016.10.007.

[4] A.K. Padhi, K.S. Nanjundaswamy, J.B. Goodenough, Phospho-olivines as PositiveElectrode Materials for Rechargeable Lithium Batteries, J. Electrochem. Soc. 144 (1997) 1188. doi:10.1149/1.1837571.

[5] A. Paolella, G. Bertoni, S. Marras, E. Dilena, M. Colombo, M. Prato, A. Riedinger, M. Povia, A. Ansaldo, K. Zaghib, L. Manna, C. George, Etched Colloidal LiFePO 4 Nanoplatelets toward High-Rate Capable Li-Ion Battery Electrodes, Nano Lett. 14 (2014) 6828-6835. doi:10.1021/nl504093w.

[6] B. Xu, D. Qian, Z. Wang, Y.S. Meng, Recent progress in cathode materials research for advanced lithium ion batteries, Mater. Sci. Eng. R Reports. 73 (2012) 51-65. doi:10.1016/J.MSER.2012.05.003.

[7] E. Zhecheva, R. Stoyanova, Stabilization of the layered crystal structure of LiNiO2 by Co-substitution, Solid State Ionics. 66 (1993) 143-149. doi:10.1016/01672738(93)90037-4.

[8] C. Delmas, I. Saadoune, A. Rougier, The cycling properties of the LixNi1-yCoyO2 electrode, J. Power Sources. 44 (1993) 595-602. doi:10.1016/0378-7753(93)80208-7.

[9] A. Rougier, I. Saadoune, P. Gravereau, P. Willmann, C. Delmasa, Effect of cobalt substitution on cationic distribution in LiNi1 - y CoyO2 electrode materials, Solid State Ionics. 90 (1996) 83-90. doi:10.1016/S0167-2738(96)00370-0.

[10] A. Manthiram, B. Song, W. Li, A perspective on nickel-rich layered oxide cathodes for lithium-ion batteries, Energy Storage Mater. 6 (2017) 125-139.

doi:10.1016/J.ENSM.2016.10.007.

[11] M.S. Whittingham, Lithium Batteries and Cathode Materials, (2004). doi:10.1021/cr020731c.

[12] W. Liu, P. Oh, X. Liu, M.-J. Lee, W. Cho, S. Chae, Y. Kim, J. Cho, Nickel-Rich Layered Lithium Transition-Metal Oxide for High-Energy Lithium-lon Batteries, Angew. Chemie Int. Ed. 54 (2015) 4440-4457. doi:10.1002/anie.201409262.

[13] H.-J. Noh, S. Youn, C.S. Yoon, Y.-K. Sun, Comparison of the structural and electrochemical properties of layered Li[NixCoyMnz]O2 $(x=1 / 3,0.5,0.6,0.7,0.8$ and 0.85) cathode material for lithium-ion batteries, J. Power Sources. 233 (2013) 121130. doi:10.1016/J.JPOWSOUR.2013.01.063.

[14] Y.-K. Sun, S.-T. Myung, B.-C. Park, J. Prakash, I. Belharouak, K. Amine, High-energy 
cathode material for long-life and safe lithium batteries, Nat. Mater. 8 (2009) 320-324. doi:10.1038/nmat2418.

[15] A. Manthiram, J.C. Knight, S.-T. Myung, S.-M. Oh, Y.-K. Sun, Nickel-Rich and Lithium-Rich Layered Oxide Cathodes: Progress and Perspectives, Adv. Energy Mater. 6 (2016) 1501010. doi:10.1002/aenm.201501010.

[16] E. Hu, X. Yu, R. Lin, X. Bi, J. Lu, S. Bak, K.-W. Nam, H.L. Xin, C. Jaye, D.A. Fischer, K. Amine, X.-Q. Yang, Evolution of redox couples in Li- and Mn-rich cathode materials and mitigation of voltage fade by reducing oxygen release, Nat. Energy. 3 (2018) 690-698. doi:10.1038/s41560-018-0207-z.

[17] M. Sathiya, A.M. Abakumov, D. Foix, G. Rousse, K. Ramesha, M. Saubanère, M.L. Doublet, H. Vezin, C.P. Laisa, A.S. Prakash, D. Gonbeau, G. VanTendeloo, J.-M. Tarascon, Origin of voltage decay in high-capacity layered oxide electrodes, Nat. Mater. 14 (2015) 230-238. doi:10.1038/nmat4137.

[18] A. Singer, M. Zhang, S. Hy, D. Cela, C. Fang, T.A. Wynn, B. Qiu, Y. Xia, Z. Liu, A. Ulvestad, N. Hua, J. Wingert, H. Liu, M. Sprung, A. V. Zozulya, E. Maxey, R. Harder, Y.S. Meng, O.G. Shpyrko, Nucleation of dislocations and their dynamics in layered oxide cathode materials during battery charging, Nat. Energy. 3 (2018) 641-647. doi:10.1038/s41560-018-0184-2.

[19] L. Mu, R. Lin, R. Xu, L. Han, S. Xia, D. Sokaras, J.D. Steiner, T.-C. Weng, D. Nordlund, M.M. Doeff, Y. Liu, K. Zhao, H.L. Xin, F. Lin, Oxygen Release Induced Chemomechanical Breakdown of Layered Cathode Materials, Nano Lett. 18 (2018) 3241-3249. doi:10.1021/acs.nanolett.8b01036.

[20] D. Zeng, J. Cabana, J. Bréger, W.-S. Yoon, C.P. Grey, Cation Ordering in Li[Ni $x$ Mn ${ }_{x}$ Co ${ }_{(1-2 x)} \mathrm{JO}_{2}$-Layered Cathode Materials: A Nuclear Magnetic Resonance (NMR), Pair Distribution Function, X-ray Absorption Spectroscopy, and Electrochemical Study, Chem. Mater. 19 (2007) 6277-6289. doi:10.1021/cm702241a.

[21] G. Sun, X. Yin, W. Yang, A. Song, C. Jia, W. Yang, Q. Du, Z. Ma, G. Shao, The effect of cation mixing controlled by thermal treatment duration on the electrochemical stability of lithium transition-metal oxides, Phys. Chem. Chem. Phys. 19 (2017) 29886-29894. doi:10.1039/C7CP05530G.

[22] P.K. Nayak, J. Grinblat, M. Levi, E. Levi, S. Kim, J.W. Choi, D. Aurbach, Al Doping for Mitigating the Capacity Fading and Voltage Decay of Layered Li and Mn-Rich Cathodes for Li-Ion Batteries, Adv. Energy Mater. 6 (2016) 1502398. doi:10.1002/aenm.201502398.

[23] L. Zhao, Q. Wu, J. Wu, Improving rate performance of cathode material Li1.2Mn0.54Co0.13Ni0.1302 via niobium doping, J. Solid State Electrochem. 22 (2018) 2141-2148. doi:10.1007/s10008-018-3912-4.

[24] A. Vasileiadis, N.J.J. de Klerk, R.B. Smith, S. Ganapathy, P.P.R.M.L. Harks, M.Z. Bazant, M. Wagemaker, Toward Optimal Performance and In-Depth Understanding of Spinel $\mathrm{Li}_{4} \mathrm{Ti}_{5} \mathrm{O}_{12}$ Electrodes through Phase Field Modeling, Adv. Funct. Mater. 28 (2018) 1705992. doi:10.1002/adfm.201705992.

[25] L. Peng, P. Xiong, L. Ma, Y. Yuan, Y. Zhu, D. Chen, X. Luo, J. Lu, K. Amine, G. Yu, Holey two-dimensional transition metal oxide nanosheets for efficient energy storage, Nat. Commun. 8 (2017). doi:10.1038/ncomms15139.

[26] X. Zhang, A.M. Bruck, Y. Zhu, L. Peng, J. Li, E. Stach, Y. Zhu, K.J. Takeuchi, E.S. Takeuchi, A.C. Marschilok, G. Yu, Probing enhanced lithium-ion transport kinetics in 2D holey nanoarchitectured electrodes, Nano Futur. 2 (2018) 035008. 
[27] D. Su, S. Dou, G. Wang, Ultrathin $\mathrm{MoS}_{2}$ Nanosheets as Anode Materials for SodiumIon Batteries with Superior Performance, Adv. Energy Mater. 5 (2015) 1401205. doi:10.1002/aenm.201401205.

[28] M. Acerce, D. Voiry, M. Chhowalla, Metallic 1T phase MoS2 nanosheets as supercapacitor electrode materials, Nat. Nanotechnol. 10 (2015) 313-318. doi:10.1038/nnano.2015.40.

[29] L. Wang, Q. Zhang, J. Zhu, X. Duan, Z. Xu, Y. Liu, H. Yang, B. Lu, Nature of extra capacity in MoS2electrodes: Molybdenum atoms accommodate with lithium, Energy Storage Mater. 16 (2019) 37-45. doi:10.1016/j.ensm.2018.04.025.

[30] D.K. Bediako, M. Rezaee, H. Yoo, D.T. Larson, S.Y.F. Zhao, T. Taniguchi, K. Watanabe, T.L. Brower-Thomas, E. Kaxiras, P. Kim, Heterointerface effects in the electrointercalation of van der Waals heterostructures, Nature. 558 (2018) 425-429. doi:10.1038/s41586-018-0205-0.

[31] J. Ding, Y. Zhou, Y. Li, S. Guo, X. Huang, MoS2Nanosheet Assembling Superstructure with a Three-Dimensional Ion Accessible Site: A New Class of Bifunctional Materials for Batteries and Electrocatalysis, Chem. Mater. 28 (2016) 2074-2080. doi:10.1021/acs.chemmater.5b04815.

[32] J. Xuan, Z. Wang, Y. Chen, D. Liang, L. Cheng, X. Yang, Z. Liu, R. Ma, T. Sasaki, F. Geng, Organic-Base-Driven Intercalation and Delamination for the Production of Functionalized Titanium Carbide Nanosheets with Superior Photothermal Therapeutic Performance, Angew. Chemie - Int. Ed. 55 (2016) 14569-14574. doi:10.1002/anie.201606643.

[33] T. Li, L. Yao, Q. Liu, J. Gu, R. Luo, J. Li, X. Yan, W. Wang, P. Liu, B. Chen, W. Zhang, W. Abbas, R. Naz, D. Zhang, Fluorine-Free Synthesis of High-Purity $\mathrm{Ti3C} 2 \mathrm{Tx}(\mathrm{T}=\mathrm{OH}, \mathrm{O})$ via Alkali Treatment, Angew. Chemie - Int. Ed. 57 (2018) 61156119. doi:10.1002/anie.201800887.

[34] M. Alhabeb, K. Maleski, T.S. Mathis, A. Sarycheva, C.B. Hatter, S. Uzun, A. Levitt, Y. Gogotsi, Selective Etching of Silicon from $\mathrm{Ti}_{3} \mathrm{SiC}_{2}$ (MAX) To Obtain 2D Titanium Carbide (MXene), Angew. Chemie. 130 (2018) 5542-5546. doi:10.1002/ange.201802232.

[35] S. Kajiyama, L. Szabova, H. linuma, A. Sugahara, K. Gotoh, K. Sodeyama, Y. Tateyama, M. Okubo, A. Yamada, Enhanced Li-Ion Accessibility in MXene Titanium Carbide by Steric Chloride Termination, Adv. Energy Mater. 7 (2017) 1-8. doi:10.1002/aenm.201601873.

[36] M.Q. Zhao, X. Xie, C.E. Ren, T. Makaryan, B. Anasori, G. Wang, Y. Gogotsi, Hollow MXene Spheres and 3D Macroporous MXene Frameworks for Na-lon Storage, Adv. Mater. 29 (2017) 1-7. doi:10.1002/adma.201702410.

[37] Y. Xia, T.S. Mathis, M.Q. Zhao, B. Anasori, A. Dang, Z. Zhou, H. Cho, Y. Gogotsi, S. Yang, Thickness-independent capacitance of vertically aligned liquid-crystalline MXenes, Nature. 557 (2018) 409-412. doi:10.1038/s41586-018-0109-z.

[38] A. Manthiram, Materials Challenges and Opportunities of Lithium Ion Batteries, J. Phys. Chem. Lett. 2 (2011) 176-184. doi:10.1021/jz1015422.

[39] B. Dunn, H. Kamath, J.-M. Tarascon, Electrical energy storage for the grid: a battery of choices., Science. 334 (2011) 928-35. doi:10.1126/science.1212741.

[40] P. Verma, P. Maire, P. Novák, A review of the features and analyses of the solid electrolyte interphase in Li-ion batteries, Electrochim. Acta. 55 (2010) 6332-6341. 
doi:10.1016/j.electacta.2010.05.072.

[41] E. Peled, S. Menkin, Review-SEl: Past, Present and Future, J. Electrochem. Soc. (2017). doi:10.1149/2.1441707jes.

[42] W. Li, A. Dolocan, P. Oh, H. Celio, S. Park, J. Cho, A. Manthiram, Dynamic behaviour of interphases and its implication on high-energy-density cathode materials in lithiumion batteries, Nat. Commun. (2017). doi:10.1038/ncomms14589.

[43] A. Arya, A.L. Sharma, Structural, microstructural and electrochemical properties of dispersed-type polymer nanocomposite films, J. Phys. D. Appl. Phys. (2018). doi:10.1088/1361-6463/aa9f69.

[44] J.B. Goodenough, Y. Kim, Challenges for Rechargeable Li Batteries, Chem. Mater. 22 (2010) 587-603. doi:10.1021/cm901452z.

[45] K.M. Abraham, Prospects and limits of energy storage in batteries, J. Phys. Chem. Lett. (2015). doi:10.1021/jz5026273.

[46] Y. Wang, X. Li, Y. Zhang, X. He, J. Zhao, Ether based electrolyte improves the performance of CuFeS2spike-like nanorods as a novel anode for lithium storage, Electrochim. Acta. (2015). doi:10.1016/j.electacta.2015.01.141.

[47] Y. Fu, A. Manthiram, Electrochemical properties of Cu2S with ether-based electrolyte in Li-ion batteries, Electrochim. Acta. (2013). doi:10.1016/j.electacta.2013.07.160.

[48] M.A. Navarra, K. Fujimura, M. Sgambetterra, A. Tsurumaki, S. Panero, N. Nakamura, H. Ohno, B. Scrosati, New Ether-functionalized Morpholinium- and Piperidiniumbased Ionic Liquids as Electrolyte Components in Lithium and Lithium-Ion Batteries, ChemSusChem. (2017). doi:10.1002/cssc.201700346.

[49] D.J. Lee, J. Hassoun, S. Panero, Y.K. Sun, B. Scrosati, A tetraethylene glycol dimethylether-lithium bis(oxalate)borate (TEGDME-LiBOB) electrolyte for advanced lithium ion batteries, Electrochem. Commun. (2012). doi:10.1016/j.elecom.2011.10.027.

[50] Y. Yamada, M. Yaegashi, T. Abe, A. Yamada, A superconcentrated ether electrolyte for fast-charging Li-ion batteries, Chem. Commun. (2013). doi:10.1039/c3cc46665e.

[51] W. Liu, D. Lin, J. Sun, G. Zhou, Y. Cui, Improved Lithium lonic Conductivity in Composite Polymer Electrolytes with Oxide-Ion Conducting Nanowires, ACS Nano. (2016). doi:10.1021/acsnano.6b06797.

[52] W. Liu, S.W. Lee, D. Lin, F. Shi, S. Wang, A.D. Sendek, Y. Cui, Enhancing ionic conductivity in composite polymer electrolytes with well-aligned ceramic nanowires, Nat. Energy. (2017). doi:10.1038/nenergy.2017.35.

[53] J. Bae, Y. Li, J. Zhang, X. Zhou, F. Zhao, Y. Shi, J.B. Goodenough, G. Yu, A 3D Nanostructured Hydrogel-Framework-Derived High-Performance Composite Polymer Lithium-Ion Electrolyte, Angew. Chemie - Int. Ed. (2018). doi:10.1002/anie.201710841.

[54] C. Yu, S. Ganapathy, N.J.J. De Klerk, I. Roslon, E.R.H. Van Eck, A.P.M. Kentgens, M. Wagemaker, Unravelling Li-lon Transport from Picoseconds to Seconds: Bulk versus Interfaces in an Argyrodite Li6PS5Cl-Li2S All-Solid-State Li-Ion Battery, J. Am. Chem. Soc. (2016). doi:10.1021/jacs.6b05066.

[55] N.J.J. De Klerk, I. Rosłoń, M. Wagemaker, Diffusion Mechanism of Li Argyrodite Solid Electrolytes for Li-Ion Batteries and Prediction of Optimized Halogen Doping: The Effect of Li Vacancies, Halogens, and Halogen Disorder, Chem. Mater. (2016). 
doi:10.1021/acs.chemmater.6b03630.

[56] J.F. Wu, W.K. Pang, V.K. Peterson, L. Wei, X. Guo, Garnet-Type Fast Li-lon Conductors with High lonic Conductivities for All-Solid-State Batteries, ACS Appl. Mater. Interfaces. (2017). doi:10.1021/acsami.7b00614.

[57] Y. Kato, S. Hori, T. Saito, K. Suzuki, M. Hirayama, A. Mitsui, M. Yonemura, H. Iba, R. Kanno, High-power all-solid-state batteries using sulfide superionic conductors, Nat. Energy. (2016). doi:10.1038/nenergy.2016.30.

[58] J. Wang, Y. Yamada, K. Sodeyama, C.H. Chiang, Y. Tateyama, A. Yamada, Superconcentrated electrolytes for a high-voltage lithium-ion battery, Nat. Commun. (2016). doi:10.1038/ncomms12032.

[59] J. Wang, Y. Yamada, K. Sodeyama, E. Watanabe, K. Takada, Y. Tateyama, A. Yamada, Fire-extinguishing organic electrolytes for safe batteries, Nat. Energy. (2018). doi:10.1038/s41560-017-0033-8.

[60] L. Suo, O. Borodin, T. Gao, M. Olguin, J. Ho, X. Fan, C. Luo, C. Wang, K. Xu, "Waterin-salt" electrolyte enables high-voltage aqueous lithium-ion chemistries, Science (80-. ). (2015). doi:10.1126/science.aab1595. 